\title{
How can we teach students if we do not know how they learn?
}

\author{
Md. Anwarul Azim Majumder
}

Lecturer, Department of Clinical Sciences, School of Medical Sciences, University of Bradford, West Yorkshire, Bradford, UK.

In recent years, the training of teachers in medical education and teaching methodology has gained momentum in most of the South-East Asian countries. ${ }^{1-4}$ Well-established functioning medical education units were established in many medical schools in the region, and regular training courses, even degrees and diplomas, are being offered on medical education to produce better teachers. ${ }^{5,6}$ The training is mainly focused on curriculum planning and development, teaching methodology, assessment of students, program evaluation etc. ${ }^{4,7}$ however, the effect of learning styles and implications of adult learning theories on students' learning received less attention. ${ }^{7}$ Students have their preferred learning styles and a number of factors tend to affect their learning. Teachers need to recognize that every student does not learn in the same way. ${ }^{8}$ Teachers should also have a clear idea regarding their students' learning preferences and styles, encouraging students to reflect on them, and designing teaching and learning interventions around them. ${ }^{9}$ How can teachers teach students if those teachers do not know how students learn? It is encouraging to note that the theory and practice of learning styles/approaches has generated great interest in medical education in recent years; ${ }^{9}$ however, their application is not practiced/applied as widely as it should be ${ }^{10}$ specially in Asian context and culture.

The key reason for the application of learning theories in medical education is the exponential growth of knowledge and information in the field of medicine which requires continuous update both for students and teachers. ${ }^{11}$ It is a real challenge to provide a huge amount of knowledge and information within a limited time period in such a way that the student can retain, remember, and effectively interpret and apply it later in their professional life. ${ }^{11}$ In response to these challenges, most medical schools in South-East Asia have undergone a pedagogic shift from the traditional approach (teacher-cantered and subject-based teaching) to student-centered learning and integrated teaching. ${ }^{5,12,13}$ In the light of these changes, the knowledge of learning styles/approaches and adult learning theories can be useful to both teachers and students. ${ }^{8,9,14}$ Teachers can tailor learning theories to relate with the learning styles and approaches of students and similarly, students could be empowered to identify and use the appropriate learning styles best suited to themselves. $^{9,14,15}$ This ultimately results in greater educational attainment and student satisfaction.

Another neglected issue in the South-East Asia region is the support which is required to provide for the students with learning disabilities (LDs). ${ }^{16}$ The numbers of students with LDs are continuing to rise in higher education. ${ }^{17}$ The worrying concern is that two-thirds to a half of these students with LDs remain undiagnosed when they start their undergraduate education and may even graduate without having their disabilities diagnosed. ${ }^{17,18}$ These students struggle with their academic abilities, receive poor grades and, as a result, develop lower perceptions of their intellectual abilities than do those students without LDs. ${ }^{19}$ All these ultimately hamper their professional practice, employment, and career progression. Appropriate and adequate educational policies, provisions, and practices help students to progress satisfactorily. ${ }^{16}$ Medical schools in South East Asia need to ensure that teachers are trained to provide specialist educational advice and support to LD students and aware of their learning preferences. $^{16}$

There are many theories that explain how adults learn and these can be used to enhance student and teacher learning. ${ }^{8,9,15}$ Malcolm Knowles first used the concept of adults learning and considered that adults learn in different ways from children. ${ }^{8} \mathrm{He}$ introduced the term 'andragogy' (andra - meaning 'man' and agogos meaning 'learning') to differentiate adult learning from pedagogy (the art and science of teaching children) and defining it as the 'art and science of helping adults learn'. ${ }^{8}$ Andragogy assumes that adults are independent and self-directing learners, have (various degrees of) experience, integrate learning to practice, are more interested in immediate problem-centered approaches and are motivated more by internal than external drives. $^{10,15}$ It is surprising that many medical schools 'more closely follow the pedagogical model' to teach medical students who are adult learners. ${ }^{15}$ Medical teachers need to examine whether their educational programs are consistent with the above-mentioned assumptions of adult learning. ${ }^{8,15}$

Taylor \& Hamdy ${ }^{9}$ summarized the theories of adult learning into several categories which are applicable to medical education: instrumental learning theories,

Correspondence: Dr. Md Anwarul Azim Majumder, Lecturer, Department of Clinical Sciences, School of Medical Sciences, University of Bradford, Bradford BD7 1DP, West Yorkshire, UK. E-mail: a.a.majumder@,bradford.ac.uk.

South East Asia Journal of Public Health 2013;3(2):70-73. (C) 2013 Majumder, publisher and licensee Public Health Foundation Bangladesh. This is an Open Access article which permits unrestricted non-commercial use, provided the original work is properly cited. DOI: http://dx.doi.org/10.3329/seajph.v3i2.20044 
humanistic theories, transformative learning theory, social theories of learning, motivational models, and reflective models. Adult learning theories should influence all aspects of health profession education, from mission and vision statements, teaching and learning, to assessment and program evaluation. ${ }^{9,10,15}$ Instrumental learning theories focus on individual experience, and include the behaviorist and cognitive learning theories. ${ }^{9}$ The design of many competency based curricula in medical education is based on behavioral theories. ${ }^{9}$ Behavior theorists define learning as nothing more than the acquisition of new behavior. Cognitive learning theories focus learning in the mental and psychological processes of the mind, not on behavior and are concerned with perception and the processing of information. ${ }^{20,21}$ Learning occurs when new knowledge is acquired or existing knowledge is modified by experience. The application of experiential learning in medical education is relevant because it focuses on developing competences and practicing skills in a specific context. ${ }^{8}$ Kolb $^{22}$ proposed a four-stage 'experiential learning cycle' model that is often referred to in describing experiential learning. According to this model, learning occurs through concrete experience, observation and reflection, abstract conceptualization and active experimentation. This theory asserts that without reflection learners would simply continue to repeat their mistakes. Reflection is a key part of experiential learning as it 'turns experience into learning, ${ }^{23}$

Humanistic theories promote individual development and are more learner-centred. ${ }^{9}$ According to this model, learners need to be empowered, internally motivated and to have control over the learning process (selfdirected learners). Self-directed learning suggests that students can plan, conduct, and evaluate their own learning. In transformative learning, students explore and use critical reflection to challenge each other's assumptions and encourage group members to consider various perspectives. ${ }^{25,26}$ Transformative learning is a route to the development of critical thinking. Social theories of learning emphasize that people are shaped in fundamental ways by their environment through learning processes. ${ }^{27}$ These theories serve as the basis for many other evidence-based health education and health promotion theories, including the social cognitive theory. ${ }^{8}$ Motivational models highlight the importance of intrinsic motivation of the students, and consider that students should possess three basic needs to sustain such motivation: autonomy, competence, and a feeling of belonging (relatedness). ${ }^{8-19}$ The reflection-change models consider that reflection leads to action and then bring desired change. ${ }^{8}$ In medical education, reflective practice may be applied to the learning of students, and equally to the professional development of the teachers. ${ }^{24}$ Such reflective practice is a key aspect of lifelong learning.$^{23}$

Widening access and improving participation in medical schools should be a crucial part of mission of medical education. ${ }^{16}$ Student cohorts in medical schools in South -East Asia consists of different ethnic, cultural and educational backgrounds. ${ }^{16,27}$ Several factors including teaching methods, educational environments, cognitive ability, pastoral support, and learning approaches contribute to the success of educational practice. ${ }^{28,29}$ Learning approaches are considered to be one of the most important factors in the success of medical education. ${ }^{30}$ There are different approaches to learning used by the students. ${ }^{31}$ Deep approach is an organized approach where emphasis is placed on understanding concepts and relating ideas, and is considered to be the preferred style of learning in medical education. There is some evidence that lecturers who take a studentfocused approach to teaching and learning will encourage students towards a deeper approach to study ${ }^{29}$ In the surface approach to learning, students usually make no distinction between new ideas and existing knowledge and treat the task as externally imposed. ${ }^{31}$ Rote learning is the typical surface approach. Biggs $^{28}$ identified a third approach to study - the strategic or achieving approach, associated with assessment. Here the emphasis is on organizing learning, specifically to obtain a high examination grade. Students who use a strategic approach and adopt either deep or superficial learning as appropriate for a particular topic, with the aim of achieving highest possible grades. ${ }^{11}$ Research showed that surface approach is more likely to result in failure in final examinations in medical schools; however, both the deep and strategic approaches are more likely to result in success. ${ }^{32}$ It was found that doctors who adopt a deep approach to learning are more likely to be life-long learners and have more tendency to pursue additional postgraduate academic training later in their professional life than those who use a surface approach. $^{33}$

Learning styles and their approaches to study also have a significant impact on both the quality of learning and their future academic success. ${ }^{14}$ In medical schools, students usually struggle to acquire large amounts of information and adapt different learning styles acquiring knowledge and information. ${ }^{34}$ Fleming mentioned that students use four different sensory modalities for assimilating knowledge and information and proposed Visual-Aural-Read/write-Kinesthetic (VARK) questionnaire. ${ }^{35} \mathrm{~A}$ visual student likes to learn visually and an aural student uses listening techniques to learn. Those with a "read/write" approach tend to like books, texts and lists for assimilating and accommodating information. A kinesthetic student likes to learn by doing - they use all sensory channels, including somatosensory, auditory, olfactory, gustative and visual. Over the past year, the VARK has been used in some countries to assess the learning style preferences of students. Samarakoon et al. ${ }^{11}$ used VARK questionnaire and found that appropriate learning approaches encourage a positive shift towards deep and strategic learning in Sri Lankan postgraduate medical students. Studies conducted in the USA $^{36}$ and Turkey ${ }^{34}$ demonstrated that the majority of first year medical students preferred multimodal learning styles in comparison to a unimodal learning style. However, Shah et al. ${ }^{37}$ found that most of the medical students in India use a 
kinesthetic approach and preferred a single mode of information presentation. This may indicate the cultural influence on learning of students in South East Asian countries.

Medicine is a field that requires a focused learning style and approach for a number of specific reasons. Teaching medicine is an ever-evolving process which requires that both students and teachers continuously update themselves. The challenge of imparting a large amount of knowledge within a limited time period in a way it is retained, remembered and effectively interpreted by a student is considerable. This has resulted in crucial changes in the field of medical education, with a shift from didactic teacher-centered and subject-based teaching to the use of interactive, problem-based, student-centered learning. Most medical school curricula have adopted new methods of teaching and learning to varying degrees. ${ }^{5}$ It has been argued that knowledge of learning styles can be useful to both teachers and students, in that teachers can tailor 'andragogy' to correlate with the learning styles of students. ${ }^{8-10,15}$ Similarly, students with knowledge of their learning styles could be empowered to identify and use the techniques of learning best suited to their individual styles, resulting in greater educational satisfaction. More research is needed in this area as little is known about the application of adult learning theories in medical education, and the use of learning preferences among medical students in South East Asia (where the culture and medical education and practice differ greatly from the Western countries).

\section{References}

1. Majumder MAA. Issues and Priorities of Medical Education Research in Asia. Ann Acad Med Singapore 2004;33:257-63.

2. Singh T, Bansal P, Sharma M. A need and necessity for faculty development: the role of medical education units in the Indian context. South East Asian J Med Educ 2008;2(1):2-6.

3. Srinivas DK, Adkoli BV. Faculty development in medical education in India. Al Ameen $J$ Med Sci 2009; 2(1):6-13.

4. Hegde P. Faculty Development Trends in Medical Education: a Review. South East Asian J Med Educ 2013, 7(2):11-6.

5. Majumder MAA, D’Souza U, Rahman S. Trends in Medical Education: Challenges and Directions for Need-based Reforms of Medical Training in South-East Asia. Indian J Med Sci 2004;58(9):369-80.

6. Amin Z, Merrylees N, Hanif A, Talukder MH. Medical education in Bangladesh. Med Teach 2008;30:243-7.

7. Mukhtar F, Chaudhry AM. Faculty development in medical institutions: where do we stand in Pakistan? J Ayub Med Coll Abbottabad 2010;22 (3):210-3.
8. Knowles A. Andragogy in Action: Applying modern principles of adult learning. San Francisco: Jossey-Bass, 1984.

9. Taylor DC, Hamdy H. Adult learning theories: implications for learning and teaching in medical education: AMEE Guide No. 83. Med Teach 2013;35(11):e1561-72.

10. Abela J. Adult learning theories and medical education: a review. Malta Med J 2009; 21:11-8.

11. Samarakoon L, Fernando T, Rodrigo C. Learning styles and approaches to learning among medical undergraduates and postgraduates BMC Med Educ 2013;13:42.

12. Majumder MAA. Development of a Culturally Relevant Operational Model for Evaluation of the Undergraduate Curriculum in the Medical Colleges of Bangladesh. [thesis]. Dundee, UK: University of Dundee, 2000.

13. Majumder MAA. A review of the undergraduate medical curriculum in Bangladesh. Bangladesh Med J 2002;31:47-9.

14. Newble DI, Entwistle NJ. Learning styles and approaches: implications for medical education Med Educ 1986;20(3):162-75.

15. Koons DC. Applying Adult Learning Theory to Improve Medical Education. [thesis]. Storrs, USA: University of Connecticut, 2004.

16. Majumder MAA, Rahman S, D'Souza UJA, Elbeheri G, Abdulrahman KB, Huq MM. Supporting medical students with learning disabilities in Asian medical schools. Adv Med Educ Pract 2010;1:31-9.

17. Rosebraugh CJ. Learning disabilities and medical schools. Med Educ 2000;34:994-1000.

18. Walters JA, Croen LG. An approach to meeting the needs of medical students with learning disabilities. Teach Learn Med 1993;5:29-35.

19. Richardson JTE, Wydell TN. The representation and attainment of students with dyslexia in UK higher education. Read Writ 200316: 475-503.

20. Piaget J. The origins of intelligence in children. New York: International University Press, 1952.

21. Gagne RM, Briggs LJ, Wagner WW. Principles of instructional design. Orlando, FL: Harcourt Brace, 1992.

22. McGill I, Beaty L. Action Learning: a guide for professional, management and educational development. Second edition London: Kogan Page, 1995.

23. Fry H, Ketteridge S, Marshall S. A handbook for teaching and learning in higher education: enhancing academic practice. 3rd ed. New York: Routledge, 2009. 
24. Boud D, Keogh R, Walker, D (eds). Reflection: Turning Experience into Learning. London: Kogan Page, 1985.

25. Mezirow JE. Fostering critical reflection in adulthood: A guide to transformative and emancipatory learning. San Francisco, CA: Jossey-Bass, 1990.

26. Mezirow JE. Transformative learning: Theory to practice. In: Welton MR, editor. In defense of the life world. New York: Suny Press, 1995.

27. Bandura, A. Social Learning Theory. New York: General Learning Press, 1971.

28. Biggs J. Student Approaches to Learning and Studying. Hawthorn, Victoria: Australian Council for Educational Research, 1987.

29. Prosser M, Trigwell K. Understanding Learning and Teaching. The Experience in Higher Education, Buckingham: The Society for Research into Higher Education and Open University Press, 1999.

30. Romanelli F, Bird E, Ryan M. Learning styles: A review of theory, application, and best practices. Am J Pharm Educ 2009;73:9.

31. Leite WL, Svinicki M, Shi Y. Attempted Validation of the Scores of the VARK: Learning
Styles Inventory With Multitrait-Multimethod Confirmatory Factor Analysis Models. Ed Psych Measure 2010;70:323-9.

32. Kleijn WC, van der Ploeg HM, Topman RM. Cognition, study habits, test anxiety, and academic performance. Psychol Rep 1994, 75(3 Pt 1):1219-26.

33. Newble DI, Hejka EJ, Whelan G. The approaches to learning of specialist physicians. Med Educ 1990;24:101-9.

34. Baykan Z, Nacar M. Learning styles of first-year medical students attending Erciyes University in Kayseri Turkey. Adv Physiol Educ 2007;31 (2):158-60.

35. VARK: A guide to learning style. The VARK Questionnaire. http://www.vark-learn.com/ english/page.asp? $\mathrm{p}=$ questionnaire. (accessed Dec 2014).

36. Lujan HL, DiCarlo SE. First-year medical students prefer multiple learning styles. $A d v$ Physiol Educ 2006;30(1):13-6.

37. Shah C, Joshi N, Mehta HB, Gokhle PA. Learning styles adopted by medical students. IRJP 2011;2 (12):227-9. 